\title{
Witnesses to an Outbreak
}

\author{
from “Luminous electrical phenomena associated with nocturnal tornadoes in Huntsville, Ala., 3 April 1974," \\ by Otha H.Vaughan Jr. and Bernard Vonnegut, in BAMS, October 1974
}

Few descriptions of lightning or other activity are to be found in accounts of the great tornado outbreak of 3 April 1974...during daylight... After dark, however, luminous phenomena were observed when the final tornadoes moved across Alabama and Mississippi. Even after midnight, when the tornadic activity had ended, satellite imagery showed that unusual lightning activity was occurring in the storm system...

Among [eyewitnesses] were scientifically experienced observers from the Marshall Space Flight Center and the Redstone Arsenal... [W]e have assembled the fol-

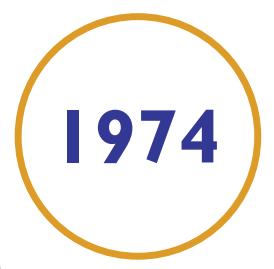
lowing excerpts...
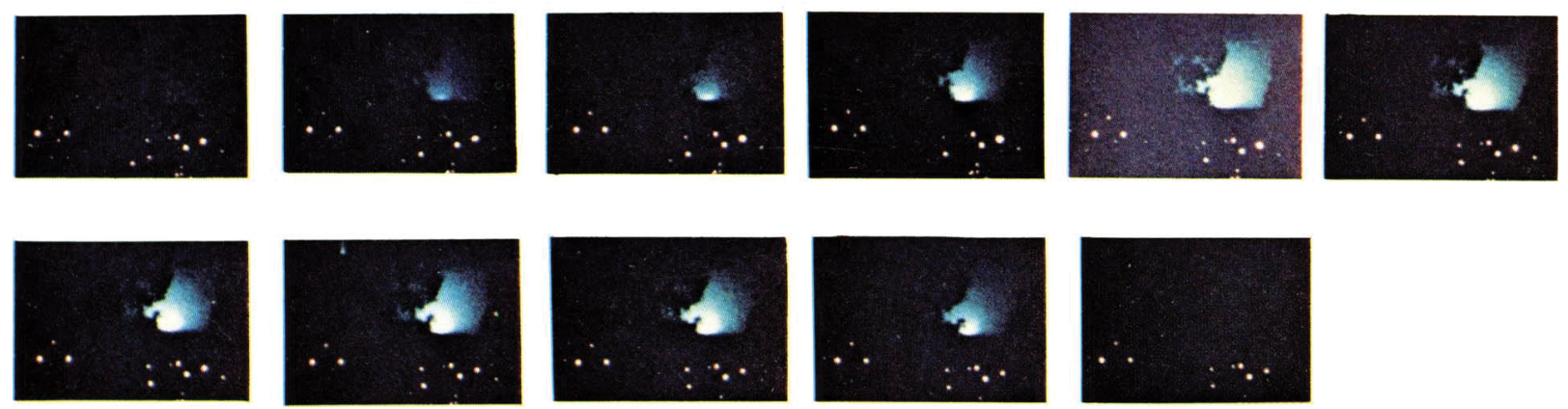

Blue glow of the Huntsville Tornado, 3 April 1974. Photograph from top of Weatherly Mountain by Otha H. Vaughan, Jr. (super 8 movie camera, Ektachrome 160, type A, 9 frames per second).

\section{Lightning of unusual frequency}

"There was lightning flashing constantly. One after the other. It was like being in a room with one of those strobe lights."

"It is like fingers reaching out from cloud to cloud and climbing along the bottom of the clouds... Like a hand crawling upside down."

\section{Lightning of different colors}

"When this thing would spark or when what I thought was power lines going down, it would start at the ground and then it would work its way up into kind of a mushroom. It would start out very intense and then it would kind of just glow. But there was one right after the other... They were rainbow colors. Some were green and some were pink and red and blue and yellow."

"[O]ne [light]...started in the cloud and then had one bolt...to ground. It seemed to start about half way up between what would look like the cloud layer and the ground and it went out in several directions... That lightning was...bluish green."
Luminous regions in clouds or sky

"I saw a very large yellow light, about the color of a carbon flame... It appeared to be sort of egg shaped-an egg standing on its end. The height...was something on the order of 800 I,000 feet... The width...possibly 400 or 500 feet... It...turned on for perhaps 2 seconds and then off."

\section{Flashes, green and blue}

"There were a lot of explosions within the tornado...maybe power lines exploding, but these bright green explosions seemed to vary in ... brightness, very light to real bright..."

"I saw this tremendous flash of green light. Now, this was like a green finger of light, a green column. It was surrounded by a real pale apple green coloration, and then that had around it somewhat of a lightish blue tinge and then from that a very, very light blue, almost like a halo."

"I noticed...a brilliant blue flash, like an electric arc... many miles away... That was followed 
about 5 to 10 seconds later by another gigantic flash of bright blue light in essentially the same location... At that time and after that, the entire sky in this area was just constant blue lightning flashes."

\section{Glow in funnel}

"There was so much of the green glow that you could see objects moving inside."

"In the lower impact areas there was a light blue discharge present-roughly that associated with the ionization of molecular oxygen. In the high impact area...we saw a slightly green glow...very typical of the ozone discharges I have seen in plasma physics. These were very faint glows from my point of observations...After the tornado...there remained, for a few minutes, a purple glow...very typical of ionized air."

\section{Ball lightning}

"At times a flash would emit red balls of fire that arched down like fireworks displays. Sometimes ten or fifteen balls would be visible. The lightning was bright enough to shut off light-operated street lights almost continuously."

To read this article in the BAMS archives, see

https://journals.ametsoc.org/doi/pdf/ I 0.I I 75//520-0477\%28| 976\%29057\%3C I 220\%3ALEPAWN\%3E2.0.CO\%3B2

\section{UNDERSTANDING EARTH'S Atmosphere \& Ocean System}

Comprehensive kit with hands-on learning tools

O Can be used at home, in class, or as a lab

O 10 basic Meteorology and Oceanography topics and over 25 activities

O Can be purchased individually or as a classroom set of 16 (including instructor set)

Contains reuseable materials designed by AMS and found nowhere else!

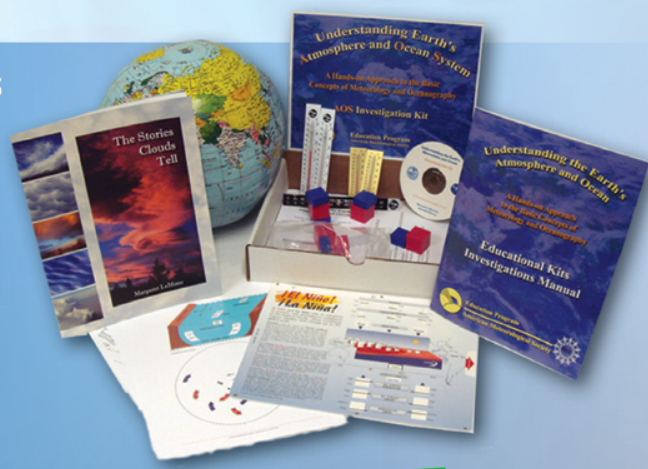

\section{To Order (check, PO, credit card):}

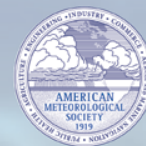

Phone:

1-800-824-0405 American Meteorological Society Education Program

Fax: 1200 New York Ave., NW, Ste 500,

$1-800-258-1176$ Washington, DC 20005-3928

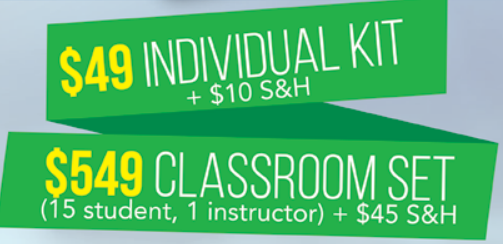

